\title{
Relationship between daily rumination time and estrus of dairy cows
}

\section{S. Reith ${ }^{1}$ and S. Hoy}

Department of Animal Breeding and Genetics, Justus Liebig University Giessen, Bismarckstrasse 16, D-35390 Giessen, Germany

\begin{abstract}
The aim of the study was to investigate whether rumination time (RT) was related to estrus in dairy cattle. On 4 farms, cows were equipped with a microphone-based sensor system that allowed continuous recording (in blocks of $2 \mathrm{~h}$ ) of RT. The analyzed data set consisted of 265 verified estrus cycles of 224 animals with artificial insemination leading to conception. The day of estrus (d 0) was defined as the day when estrus was identified either by measurement of physical activity or by visual observation. In estrous cows, RT was significantly reduced. With a duration of 355 $\mathrm{min} / \mathrm{d}$, the minimum RT was found on the day of estrus compared with the base level of $429 \mathrm{~min} / \mathrm{d}$ during the reference period (the mean of $3 \mathrm{~d}$ before and $3 \mathrm{~d}$ after estrus). The average decrease in RT was $17 \%$ (74 min), ranging between -71 and $+16 \%$ among animals. Herd and parity affected the RT decrease during estrus. Among the 4 analyzed herds, the RT decrease of cows in estrus ranged between $14 \%(60 \mathrm{~min} / \mathrm{d})$ and $24 \%$ (94 $\mathrm{min} / \mathrm{d}$ ). The decrease in RT was more pronounced in primiparous than in mature cows. In conclusion, RT is reduced on the day of estrus on average. The RT decrease during estrus was characterized by high variation among cows.
\end{abstract}

Key words: rumination time, estrus, dairy cow

\section{INTRODUCTION}

Rumination time (RT) is an appropriate parameter for early identification of metabolic disorders such as ruminal acidosis. Saliva secretion and rumen health are closely associated with daily RT (Maekawa et al., 2002). In addition, Murphy et al. (1983) noted that RT could be used for monitoring of ration composition and feeding practices.

Measurements of RT implemented by technical methods; for example, pressure transducers (Kaske et al., 2002) or piezo disks integrated within a cow's halter

Received January 3, 2012.

Accepted July 10, 2012.

${ }^{1}$ Corresponding author: Stefanie.Reith@agrar.uni-giessen.de
(Yang and Beauchemin, 2006), are mostly invented for research purposes. Recently, a microphone-based system (HR-Tag, SCR Engineers Ltd., Netanya, Israel) became commercially available for automatic recording of RT data. Rejection of feed boluses and mastication produce sounds that are registered by the acoustic sensor (Burfeind et al., 2011) and can be separated from sounds related to eating (Adin et al., 2009).

Schirmann et al. (2009) and Burfeind et al. (2011) found a high correlation $(\mathrm{r}=0.88$ and $\mathrm{r}=0.93$, respectively) between RT obtained from the HR-Tag and visual observation. Although RT can be used for monitoring the metabolic health of dairy cows, it is not known whether RT is influenced by fertility and reproductive management routines. A change that seems to be clearly associated with estrus behavior and that is pronounced in many cows is the increase in physical activity. Arney et al. (1994) and Schofield et al. (1991) observed a clear increase in the number of steps, $300 \%$ and $230 \%$, respectively. Maltz et al. (1997) reported decreased milk yield during estrus as well as a decrease in daily $\mathrm{BW}$ accompanied by a significant reduction in food consumption. The aim of the study was to investigate whether RT was related to estrus in dairy cattle. A second objective was to determine the effect of lactation number on RT.

\section{MATERIALS AND METHODS}

\section{Animals and Housing}

The study was carried out on 4 farms, and herd size ranged from 50 to 70 lactating Holstein-Friesian dairy cows. The cows were housed in freestall barns with a free cow traffic routine that implied cows always had access to the cubicles, feeding areas, and automatic milking system (AMS). The animals were fed a TMR ad libitum throughout lactation. The ration consisted of grass silage and maize silage as roughage components, supplemented with concentrated feed to fulfill energy and protein requirements. Concentrates were supplied according to production level in the milking robot or in a separate feeding station. Cows were fed twice daily at approximately $0800 \pm 1 \mathrm{~h}$ and $1700 \pm 1 \mathrm{~h}$. Cows were milked by a milking robot (Astronaut A3, Lely Ltd., 
Maassluis, the Netherlands). The cows could choose when and how often they were milked in the AMS, and their individual electronic tags were recorded (ID and individual cow data) in the AMS. The average 305-d milk production per cow was $9,800 \mathrm{~kg}$ (herd 1), 10,500 $\mathrm{kg}$ (herd 2), and 10,000 $\mathrm{kg}$ (herds 3 and 4).

After calving, reproductive management included a waiting period of $76 \pm 30 \mathrm{~d}$. The waiting period was determined based on daily milk yield and BCS of the cow. Calving to conception interval averaged $157 \mathrm{~d}$ (farm 1), $120 \mathrm{~d}$ (farm 2), $124 \mathrm{~d}$ (farm 3), and $123 \mathrm{~d}$ (farm 4). The herd managers identified estrus by visual observation and activity measurement. Physical activity was recorded by the HR-Tag monitoring system (SCR Engineers Ltd.). The cows calved year round and were artificially inseminated by the farm manager or veterinarian. In 126 cases $(47.5 \%)$ of all analyzed estrus cycles, first AI led to pregnancy. Second AI was successful in $30.6 \%$, and pregnancy was achieved after more than 2 inseminations in $21.9 \%$. Diagnosis of pregnancy was carried out by ultrasonography $29 \mathrm{~d}$ after AI or by rectal palpation $42 \mathrm{~d}$ after AI.

\section{Study Design}

In total, 279 estrus cycles were available for study. Because of missing rumination data in 14 cases, the data set was reduced to 265 estrus cycles of 224 cows. All cycles analyzed led to conception. The day of estrus was defined as the day when estrus was detected either by measurement of physical activity (farms 2, 3, and 4) or by visual observation (farm 1). Insemination was performed by the herdsman in farms 2,3 , and 4 ; the day of estrus detection was identical to the day of AI. Cows of farm 1 were inseminated by a veterinarian; in $30 \%$ of estrus events monitored on farm 1, the day of estrus was the day before AI. Deviations in RT during estrus were detected by comparing the RT value on the day of estrus with RT values of the reference period (the mean of $3 \mathrm{~d}$ before and $3 \mathrm{~d}$ after estrus). Therefore, changes in RT were collected during each cow's peri-estrus period around the successful insemination. Despite a certain degree of inaccuracy concerning timing of estrus (estrus can be initiated at any time), the measurements of RT recorded in 2-h intervals were arithmetically averaged to one value per day for further analyses.

Cow data and reproductive data (calving, estrus and insemination data, pregnancy determination) were obtained directly from the herdsman or retrieved from the management software. The following data were recorded for each animal: herd, calving date, lactation number (LN), insemination date, number of inseminations, service period, calving to conception interval, duration of $\mathrm{RT}$ on $\mathrm{d} 0$ and averaged over $\mathrm{d}-3$ to -1 and
+1 to +3 . The LN of the cows ranged from 1 to 10 . To analyze the possible effect of $\mathrm{LN}$ on RT, the cows were classified into 4 groups: LN 1, LN 2, LN 3, and LN $>3$.

\section{Measurement of RT}

For the automatic sensor-based detection of RT, the HR-Tag (SCR Engineers Ltd.) was used. The tag is attached to the left side of each cow's neck with a strap. A microphone enclosed within a plastic cover continuously records RT data in blocks of $2 \mathrm{~h}$. The output data consist of cow RT, chewing rhythm, and the interval between feed boluses (SCR, 2011) and are analyzed by algorithms inside the tag. The current measured data are compared with the stored pattern in a microprocessor. In the memory of the HR-Tag, data of RT can be averaged and stored in 2-h intervals up to $24 \mathrm{~h}$. All required data are transferred to receiver units installed in the AMS and sent to the management software on the farm computer. Based on validation trials (Schirmann et al., 2009; Burfeind et al., 2011), the HR-Tag works accurately for recording RT in dairy cows. The 2-h means of RT were used for further analyses in our study.

\section{Statistical Analysis}

Statistical analyses of RT data were performed using the program package SPSS 18.0 (SPSS Inc., Chicago, IL) and SAS 9.2 (SAS Institute Inc., Cary, NC). First, descriptive statistics were used for all variables. Rumination time and RT decrease during estrus were normally distributed as assessed by the KolmogorovSmirnov and Shapiro-Wilk tests. The RT data during estrus of cows were analyzed by using the MIXED procedure of SAS (SAS Institute Inc.). The following factors were included in the model:

$\mathrm{Y}_{\mathrm{ijklmn}}=\mu+\mathrm{h}_{\mathrm{i}}+\mathrm{p}_{\mathrm{j}}+\mathrm{ai}_{\mathrm{k}}+\mathrm{day}_{\mathrm{l}}+\mathrm{cow}_{\mathrm{m}}\left(\mathrm{h}_{\mathrm{i}}\right)+\mathrm{e}_{\mathrm{ijklmn}}$,

where $\mathrm{Y}_{\mathrm{ijklmn}}=$ the variable $\mathrm{RT}, \mu=$ the intercept, $\mathrm{h}_{\mathrm{i}}=$ the fixed effect of herd ( $\mathrm{i}=1$ to 4$), \mathrm{p}_{\mathrm{j}}=$ the fixed effect of parity group $(\mathrm{j}=1,2,3$, and $>3)$, ai $\mathrm{i}_{\mathrm{k}}=$ the fixed effect of the number of AI $(1,2$, and $>2)$, day $=$ the fixed effect of day $(\mathrm{l}=-3$ to 3$), \operatorname{cow}_{\mathrm{m}}\left(\mathrm{h}_{\mathrm{i}}\right)=$ the random effect of cow within herd, and $\mathrm{e}_{\mathrm{ijklmn}}=$ the random residual error. Further interactions between fixed effects were not included in the model because they were not found to be significant.

In a second analysis for each estrus, the decrease in RT was analyzed with the following fixed model (GLM):

$$
\mathrm{Y}_{\mathrm{ijkl}}=\mu+\mathrm{h}_{\mathrm{i}}+\mathrm{p}_{\mathrm{j}}+\mathrm{ai}_{\mathrm{k}}+\mathrm{e}_{\mathrm{ijkl}} \text {, }
$$




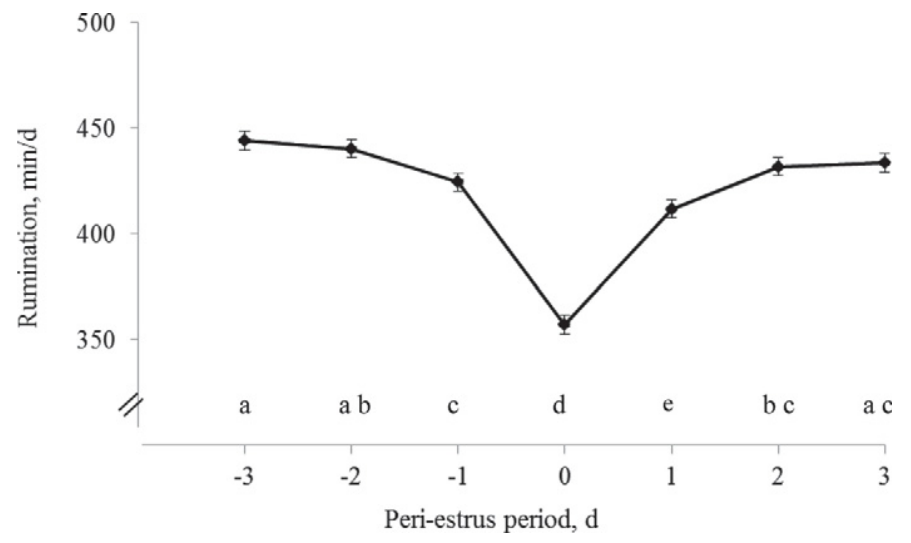

Figure 1. Dynamics of rumination time during the peri-estrus period (least squares means; bars indicate SEM) for 265 estrus events leading to pregnancy of the cow. Significance is represented by different letters $(P<0.05)$.

where effects are explained as above and $\mathrm{Y}_{\mathrm{ijkl}}=$ the variable RT decrease. Because very few cows had data in more than one parity, the random effect of cow was ignored.

\section{RESULTS}

Rumination time of dairy cows was considerably affected by day of estrus (Figure 1). In the reference period, cows spent $429( \pm 107) \mathrm{min} / \mathrm{d}$ ruminating. The duration of RT was significantly reduced on the day of estrus compared with all other days. The minimum level of daily RT was found on d 0 with $355 \mathrm{~min} / \mathrm{d}$, and RT decreased from $442 \mathrm{~min} / \mathrm{d}(\mathrm{d}-3)$ to $438 \mathrm{~min} / \mathrm{d}(\mathrm{d}-2)$ and $422 \mathrm{~min} / \mathrm{d}(\mathrm{d}-1)$. Cows reduced RT by about 16 min from $d-2$ to $d-1$. The decrease in RT from $d-1$ to the day of estrus was $67 \mathrm{~min}$. After estrus, daily RT duration increased from $409 \mathrm{~min} / \mathrm{d}$ (d 1) to $429 \mathrm{~min} / \mathrm{d}$ (d 2) and $431 \mathrm{~min} / \mathrm{d}$ (d 3). With an increase in RT of 55 min from the day of estrus to d 1, the pre-estrus decrease was not quite compensated. From d 1 to d 2, RT was enhanced further by about $22 \mathrm{~min}$. On average, RT during estrus was shortened by $17 \%$ (74 min). The

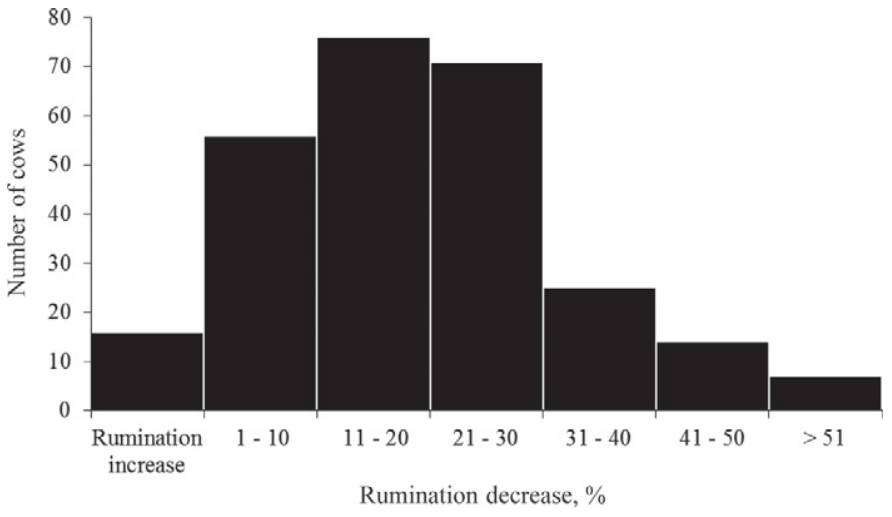

Figure 2. Distribution of the number of cows with different decreases (\%) in rumination time during estrus.

repeatability of RT for cow (81\%) was calculated as the ratio between variance for cows within herd divided by the sum of cow variance and error variance.

Large individual differences in RT decrease during estrus were found among analyzed animals and estrus periods, respectively. The distribution of RT decrease is shown in Figure 2. Out of 265 analyzed estrus events, $94 \%$ were associated with a decline in RT. Decline in $\mathrm{RT}$ ranged from $-0.9 \%$ (4 $\mathrm{min} / \mathrm{d})$ to $-71 \%(247$ $\mathrm{min} / \mathrm{d})$ relative to the base value. In 16 cases (6\%), estrus was associated with increased RT. Cows in herd 1 and cows in herd 4, respectively, reduced RT from 474 and $480 \mathrm{~min} / \mathrm{d}$ (reference period) to 396 and $389 \mathrm{~min} / \mathrm{d}$ on the day of estrus. With $385 \mathrm{~min} / \mathrm{d}$ in the reference period and $291 \mathrm{~min} / \mathrm{d}$ during estrus, the lowest value of RT was found in dairy cows of herd 2. Compared with cows in herd 2, cows in the other 3 herds chewed the cud between 82 and 105 min longer per day (Table 1).

The extent of the decrease in RT during estrus was influenced by parity (Figure 3). The decrease in daily RT during estrus was less pronounced with increasing LN. Primiparous cows decreased RT, on average, by about $98 \mathrm{~min} / \mathrm{d}$, whereas cows with $\mathrm{LN}>3$ showed a decline in RT, on average, of $69 \mathrm{~min} / \mathrm{d}$ in estrus compared with the baseline level. The difference in RT decline between

Table 1. Means of rumination time during reference period and during estrus, and mean rumination decrease in estrous cows in 4 farms $^{1}$

\begin{tabular}{|c|c|c|c|c|c|}
\hline \multirow[b]{2}{*}{ Herd } & \multirow[b]{2}{*}{$\begin{array}{c}\text { Cows, } \\
\mathrm{n}\end{array}$} & \multicolumn{2}{|c|}{ Rumination time, $\min / \mathrm{d}$} & \multirow[b]{2}{*}{$\begin{array}{c}\text { Rumination } \\
\text { decrease, min/d }\end{array}$} & \multirow[b]{2}{*}{$\begin{array}{l}\text { Ruminatior } \\
\text { decrease, \% }\end{array}$} \\
\hline & & $\begin{array}{l}\text { Reference } \\
\text { period }^{2}\end{array}$ & $\begin{array}{c}\text { Day of } \\
\text { estrus (d } 0)\end{array}$ & & \\
\hline 1 & 91 & 474 & 396 & 78 & 16 \\
\hline 2 & 48 & 385 & 291 & 94 & 24 \\
\hline 3 & 61 & 433 & 373 & 60 & 14 \\
\hline 4 & 65 & 480 & 389 & 91 & 19 \\
\hline
\end{tabular}

${ }^{1}$ Standard deviation of rumination decrease was $13 \%$.

${ }^{2}$ Reference period: mean of $\mathrm{d}-3,-2,-1,1,2$, and 3 . 


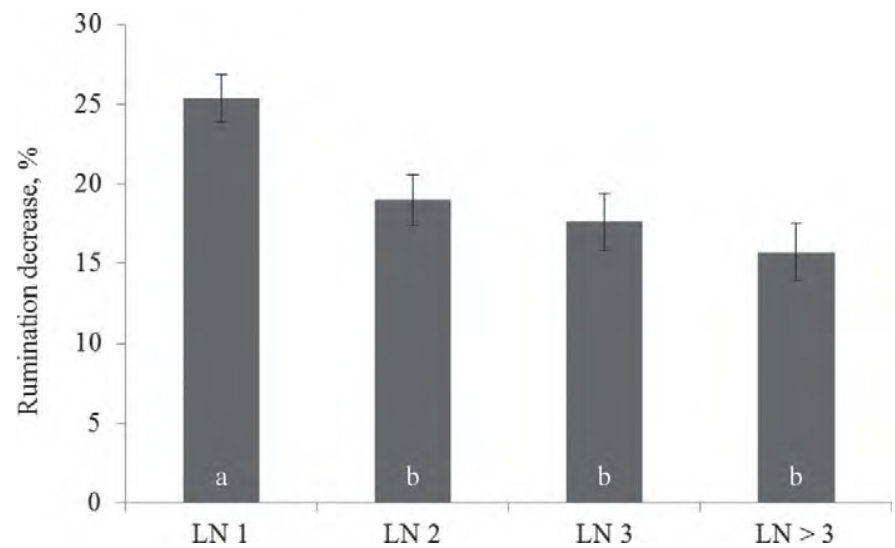

Figure 3. Decrease in daily rumination time on the day of estrus compared with the reference period $(\mathrm{d}-3$ to -1 and +1 to +3$)$ in dependence on lactation number (LN). Results are group least squares means (bars indicate SEM) for cows in parities 1 to $>3$ (LN 1 to LN $>3)$. Bars with different letters $(\mathrm{a}, \mathrm{b})$ are significantly different $(P<$ $0.05)$ from each other (LN 1: $\mathrm{n}=78, \mathrm{LN} 2: \mathrm{n}=68, \mathrm{LN} 3: \mathrm{n}=55, \mathrm{LN}$ $>3: \mathrm{n}=64$ ).

primiparous and older cows was significant. Compared with multiparous cows (cows with $\mathrm{LN}>1$ ), the decrease in RT in primiparous cows was about 23 min more pronounced during estrus.

\section{DISCUSSION}

The current study showed that chewing the cud was influenced by the onset of estrus in cows. Daily RT quantifies behavioral changes and completes the picture of increased activity and restlessness (Arney et al., 1994; Roelofs et al., 2005), reduced lying time (Brehme et al., 2006), and decreased milk yield and feed intake associated with a decrease in BW (Maltz et al., 1997). During the reference period (the mean of $3 \mathrm{~d}$ before and $3 \mathrm{~d}$ after estrus), the basal RT averaged $429 \mathrm{~min} / \mathrm{d}$, which is consistent with results of other studies. By means of HR-Tag measurements, Adin et al. (2009) recorded a daily RT between 428 and $482 \mathrm{~min}$. In all estrus cycles, the minimum value of $\mathrm{RT}$ was $357 \mathrm{~min} / \mathrm{d}$, registered on the day of estrus. The peri-estrus period was assigned into day categories. The day of estrus (d 0), mostly identical to the day of successful AI, was defined as the calendar day when estrus was detected by activity measurement or visual observation. Given the fact that estrus is initiated at any time of day, classification is difficult, as is described in other studies (Schofield et al., 1991; Arney et al., 1994). This may lead to inaccurate definitions of the exact day of estrus $(\mathrm{d} 0)$. The onset of estrus is usually gradual and occurs over several hours. This may also explain why $\mathrm{d}-1$ and $\mathrm{d} 1$ showed reduced $\mathrm{RT}$, and that could have affected $\mathrm{d}-2$ and 2 as well. During estrus, RT was reduced by $17 \%$ (74 min).
To our knowledge, this effect has not been reported previously. A plausible explanation might be that the decline in RT is closely linked to the increase in physical activity recognized one of the first signs of a cow initiating estrus behavior. Compared with cows on nonestrus days, cows in estrus show a considerable increase in activity behavior, restlessness, mounting, standing to be mounted, chin rubbing, and sniffing (Phillips and Schofield, 1990; Van Vliet and van Eerdenburgh, 1996). An obvious increase in the number of steps was detected in several pedometer studies (Arney et al., 1994; Roelofs et al., 2005). Arney et al. (1994) observed activity gradually increasing $3 \mathrm{~d}$ before estrus and decreasing after reaching peak value. Rumination shows a reverse dynamic, with a gradual decrease starting $2 \mathrm{~d}$ before onset of estrus. The expression of estrus is regulated by estrogens, especially estradiol-17 $\beta$ (Allrich, 1994; Roelofs et al., 2010), reaching peak level $1 \mathrm{~d}$ before estrus (Lopez et al., 2004). Three days after the day of estrus, estradiol concentration returns to the basal level (Mondal et al., 2006). One of the main effects of these steroids is the enhancement of activity behavior, which is negatively correlated with RT. In addition, estrogens affect dietary behavior by reducing appetite and feed consumption (Uphouse and Maswood, 1998; Mondal et al., 2006). Rumination time is strongly associated with daily feed intake (Welch, 1982; Kaske et al., 2002). During estrus, cows spend less time feeding. Phillips and Schofield (1990) observed a reduction in feeding time of between 5 and 20\%. Because of lowered feed intake, Maltz et al. (1997) reported a decrease in daily BW limited to 1 to $3 \mathrm{~d}$ during estrus. Restlessness caused by estrus reduces lying time. Brehme et al. (2006) noted that estrous cows do not lie down for 6 to $17 \mathrm{~h}$. In view of the fact that cows spend more time on rumination while lying down in cubicles (Nørgaard et al., 2003), we assume that reduced lying time impedes RT of cows in estrus. Furthermore, Brehme et al. (2006) showed that lying time is a useful trait to identify cows with low estrus intensity. Weak estrus events are rarely observed by the herd manager.

Rumination behavior was not affected similarly in all estrous animals. Dairy cows of one herd in the current study exhibited marked variation in the degree of RT decline during estrus, even when fed and managed similarly to cows of the other herds. The variation in RT decrease, including the values of the cows on the 4 analyzed farms, indicate a high variability of -71 to $+16 \%$ among animals. Not all bovine animals in estrus show equal intensity and duration of estrus (Van Vliet and van Eerdenburgh, 1996). Allrich (1994) noted a range from 3 to $28 \mathrm{~h}$ in duration of estrus.

According to Maekawa et al. (2002), multiparous cows spend more time ruminating than do primiparous 
cows. Compared with that in cows of high LN $(\mathrm{LN}>3)$ in the current study, the RT decline of young cows (LN 1) was increased by $23 \mathrm{~min} / \mathrm{d}$. The greater decrease in RT in primiparous cows is likely associated with activity behavior. Verifiable higher activity values occur in first-lactation cows during estrus (López-Gatius et al., 2005; Yániz et al., 2006). Roelofs et al. (2005) noted an increase in the number of steps taken by primiparous animals. Estrus behavior by young cows was about $3 \mathrm{~h}$ longer than that observed in older cows. López-Gatius et al. (2005) observed that cows' activity at estrus was reduced by $21.4 \%$ with each additional lactation.

\section{CONCLUSIONS}

On average, daily RT at estrus was significantly reduced compared with that on nonestrus days. However, our results indicated high variation in the RT decrease at estrus. Further research that includes factors such as accuracy, error rate, sensitivity, and specificity for different threshold values in RT decrease is necessary to determine whether RT is an indicator, alone or in combination with other parameters such as measurements of physical activity, of estrus in dairy cows.

\section{REFERENCES}

Adin, G., R. Solomon, M. Nikbachat, A. Zenou, E. Yosef, A. Brosh, A Shabtay, S. J. Mabjeesh, I. Halachmi, and J. Miron. 2009. Effect of feeding cows in early lactation with diets differing in roughageneutral detergent fiber content on intake behavior, rumination, and milk production. J. Dairy Sci. 92:3364-3373.

Allrich, R. D. 1994. Endocrine and neural control of estrus in dairy cows. J. Dairy Sci. 77:2738-2744.

Arney, D. R., S. E. Kitwood, and C. J. C. Phillips. 1994. The increase in activity during oestrus in dairy cows. Appl. Anim. Behav. Sci. $40: 211-218$.

Brehme, U., U. Stollberg, R. Holz, and T. Schleusener. 2006. ALT pedometer - A new sensor-aided measurement system for improvement in oestrus detection. Res. Agric. Eng. 52:1-10.

Burfeind, O., K. Schirmann, M. A. G. von Keyserlingk, D. M. Veira, D. M. Weary, and W. Heuwieser. 2011. Technical note: Evaluation of a system for monitoring rumination in heifers and calves. J. Dairy Sci. 94:426-430.

Kaske, M., M. Beyerbach, Y. Hailu, W. Göbel, and S. Wagner. 2002. The assessment of the frequency of chews during rumination enables an estimation of rumination activity in hay-fed sheep. J. Anim. Physiol. Anim. Nutr. (Berl.) 86:83-89.

Lopez, H., L. D. Satter, and M. C. Wiltbank. 2004. Relationship between level of milk production and estrous behavior of lactating dairy cows. Anim. Reprod. Sci. 81:209-223.
López-Gatius, F., P. Santolaria, I. Munder, and J. L. Yániz. 2005 Walking activity at estrus and subsequent fertility in dairy cows. Theriogenology 63:1419-1429.

Maekawa, M., K. A. Beauchemin, and A. Christensen. 2002. Effect of concentrate level and feeding management on chewing activities, saliva production, and ruminal $\mathrm{pH}$ of lactating dairy cows. J. Dairy Sci. 85:1165-1175.

Maltz, E., S. Devir, J. H. M. Metz, and H. Hogeveen. 1997. The body weight of dairy cows. I. Introductory study into body weight changes in dairy cows as a management aid. Livest. Prod. Sci. $48: 175-186$.

Mondal, M., C. Rajkhowa, and B. S. Prakash. 2006. Relationship of plasma estradiol-17 $\beta$, total estrogen, and progesterone to estrus behaviour in mithun (Bos frontalis) cows. Horm. Behav. 49:626633.

Murphy, M. R., R. L. Baldwin, M. J. Ulyatt, and L. J. Koong. 1983. A quantitative analysis of rumination patterns. J. Anim. Sci $56: 1236-1240$

Nørgaard, P., N. Rørbech, and P. M. Christensen. 2003. Effect of slope of cubicle floor on lying and ruminating behavior in cattle tied in experimental box stalls. Pages $282-287$ in Proc. 5th Int. Dairy Housing Conf., Fort Worth, TX. Am. Soc. Agric. Eng., St. Joseph, MI.

Phillips, C. J. C., and S. A. Schofield. 1990. The effects of environment and stage of the oestrous cycle on the behaviour of dairy cows. Appl. Anim. Behav. Sci. 27:21-31.

Roelofs, J., F. López-Gatius, R. H. F. Hunter, F. J. C. M. van Eerdenburg, and Ch. Hanzen. 2010. When is a cow in estrus? Clinical and practical aspects. Theriogenology 74:327-344.

Roelofs, J. B., F. J. C. M. van Eerdenburg, N. M. Soede, and B. Kemp. 2005. Pedometer readings for estrous detection and as predictor for time of ovulation in dairy cattle. Theriogenology 64:1690-1703.

Schirmann, K., M. A. G. von Keyserlingk, D. M. Weary, D. M. Veira and W. Heuwieser. 2009. Technical note: Validation of a system for monitoring rumination in dairy cows. J. Dairy Sci. 92:6052-6055.

Schofield, S. A.. C. J. C. Phillips, and A. R. Owens. 1991. Variation in the milk production, activity rate and electrical impedance of cervical mucus over the oestrus period of dairy cows. Anim. Reprod. Sci. 24:231-248.

SCR Engineers Ltd. 2011. Rumination Monitoring-The HR Tag ${ }^{\mathrm{TM}}$ Accessed Oct. 10, 2011. http://www.scrdairy.com/HRTag.asp.

Uphouse, L., and S. Maswood. 1998. Estrogen Action, Behavior. Pages 59-70 in Encyclopedia of Reproduction. Vol. 2. E. Knobil, and J. D. Neill, ed. Academic Press, San Diego, CA.

Van Vliet, J. H., and F. J. C. M. van Eerdenburgh. 1996. Sexual activities and oestrus detection in lactating Holstein cows. Appl. Anim. Behav. Sci. 50:57-69.

Welch, J. G. 1982. Rumination, particle size and passage from the rumen. J. Anim. Sci. 54:885-894.

Yang, W. Z., and K. A. Beauchemin. 2006. Physically effective fiber: Method of determination and effects on chewing, ruminal acidosis, and digestion by dairy cows. J. Dairy Sci. 89:2618-2633.

Yániz, J. L., P. Santolaria, A. Giribet, and F. López-Gatius. 2006. Factors affecting walking activity at estrus during postpartum period and subsequent fertility in dairy cows. Theriogenology 66:1943-1950. 